\title{
Alimentación Saludable: Líquidos ${ }^{1}$
}

Linda B. Bobroff y Luisa Oliver-Cordero²

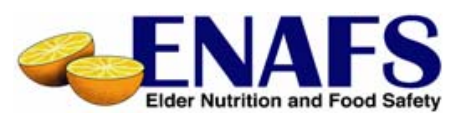

\section{¿Por qué es el agua tan importante?}

Más de la mitad del peso de una persona adulta es agua. El agua es el principal componente de todos los fluidos del cuerpo humano. Los fluidos se encargan de llevar los nutrientes a todas las células del cuerpo y también de remover los residuos que se

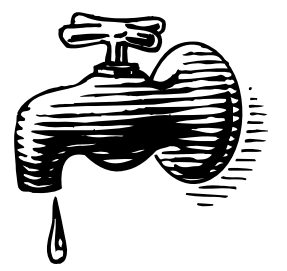
producen. Nuestro cuerpo no puede funcionar sin la cantidad de agua adecuada.

El agua ayuda a:

$\checkmark$ Convertir los alimentos en energía

$\checkmark$ Regular la temperatura corporal

$\checkmark$ Proteger y amortiguar nuestros órganos vitales

$\checkmark$ Mantener su intestino con deposiciones "regulares"

\section{¿Qué ocurre si no tomamos una cantidad suficiente de agua?}

Cuando tomamos una cantidad de agua inferior a la que perdemos, nuestro cuerpo se deshidrata. Perdemos agua a través de la orina, el sudor y las heces. Recuperamos agua cuando la bebemos directamente o en otros líquidos. También ingerimos agua a través de los alimentos, especialmente las frutas y los vegetales.

¡Un tercio de las personas mayores de 65 años padecen una deshidratación moderada!

Un consumo bajo de líquidos o deshidratación puede causar:

$\checkmark$ Dificultades al tragar

$\checkmark$ Sequedad de la boca debido a la baja producción de saliva

$\checkmark$ Dolores de cabeza

$\checkmark$ Fatiga

$\checkmark$ Perdida de apetito

$\checkmark$ Sequedad en los ojos

$\checkmark$ Calambres musculares

$\checkmark$ Enfermedades de piedras en los riñones

\section{¿Por qué es el consumo de líquidos especialmente importante en las personas mayores?}

La deshidratación es común en las personas mayores. Las posibles causas son:

$\checkmark$ No darse cuenta que tiene sed

$\checkmark$ Capacidad reducida de concentrar la orina

$\checkmark$ Restricción de fluidos por decisión propia

1. The English version of this Spanish document is Healthy Eating:Liquids (FCS8569). Este documento, FCS8569-Span, pertenece a una serie del Departamento de Ciencias de la Familia, Juventud y Comunidad, Servicio de Extensión Cooperativo de la Florida, Instituto de Alimentos y Ciencias Agrícolas, Universidad de la Florida. Fecha de publicación: septiembre 1999. Revisado: marzo 2007.

2. Linda B. Bobroff, Ph.D., RD, LD/N., profesora, Departamento de Ciencias de la Familia, Juventud y Comunidad, Servicio de Extensión Cooperativo de la Florida, Instituto de Alimentos y Ciencias Agrícolas, Universidad de la Florida, y Luisa Oliver-Cordero, anteriormente con la Universidad de la Florida. Traducción por Sergio Romero anteriormente con la Universidad de la Florida. 
Necesitamos tomar la suficiente cantidad de agua y otros líquidos para mantenernos hidratados. Como las personas mayores pueden no darse cuenta de que tienen sed, deben de tener un plan de consumo de líquidos.

\section{¿Cuanto líquido debemos de beber?}

La mayoría de las personas mayores necesitan beber alrededor de 6 a 8 tazas de líquidos al día. La cantidad necesaria depende de:

- El peso corporal

- El nivel de actividad

- El estado de salud

- El ambiente

Los factores que incrementan las necesidades de líquidos son:

- Comer alimentos con alto contenido en fibras o tomar suplementos de fibra

- Tomar algunos medicamentos, especialmente diuréticos para reducir la presión arterial

- Clima caluroso

- Actividad física vigorosa

\section{¿Que tipo de líquidos son los mejores?}

Tome líquidos que sean de su agrado. Limite el consumo de líquidos que contengan mucha azúcar o sodio. Beba agua y alguno de los siguientes líquidos con alto contenido de nutrientes a diario:

$\checkmark$ Jugos de fruta (100\% jugo, unas 6 onzas diarias son suficientes)

$\checkmark$ Jugos vegetales (de bajo contenido en sodio)
Leche de bajo contenido en grasa

Sopas de vegetales o a base de leche

\section{Consejos para beber más agua}

Puede incrementar su consumo diario de agua siguiendo alguno de los siguientes consejos. ¡Pruebe a ver cual de estas ideas funciona mejor para usted!

Comience el día con un vaso de agua.

Beba un vaso de agua $1 / 2$ hora antes de cada comida.

Cuando tome algún medicamento, hágalo con un buen vaso de agua (Mejor opción para la mayoría de los medicamentos. Consulte con su farmacéutico).

Beba un vaso de agua cuando pase tiempo al aire libre y también cuando regrese a la casa.

Llene una botella de agua y

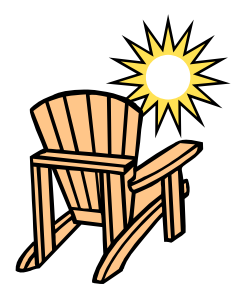
llévela con usted durante el día.

\section{¿Como saber si estamos bien hidratados?}

Seguramente no tenga problemas de deshidratación si nota que sus ojos están húmedos y no tiene problemas produciendo lágrimas.

\section{¿Donde puedo conseguir más información fiable?}

Consulte con una dietista registrada (RD). Puede encontrar un RD en su área, consultando con el número gratuito de la American Dietetic Association, 1-800-3661655 (disponible en Inglés y Español). Página Web: http://www.eatright.org

También puede llamar al agente de extensión local de su condado. Busque en 
las páginas azules del libreto telefónico por “Cooperative Extension Service”. En el estado de la Florida puede encontrar esta información visitando la página Web de la Universidad de Florida, IFAS Web de Servicios de Extensión:

http://extension.ifas.ufl.edu

Otras páginas Web con información fiable:

$\checkmark$ National Agricultural Library, U.S.

Department of Agriculture: http://www.nutrition.gov

(Recursos e información sobre nutrición y salud)

$\checkmark$ National Library of Medicine: http://medlineplus.gov (Información sobre medicamentos, términos médicos, directorio de proveedores y más)

$\checkmark$ U.S. Department of Agriculture: http://www.usda.gov/cnpp. (Educación para adultos y niños sobre nutrición, incluyendo la pirámide de alimentos, normas dietéticas, contenido nutritivo y más) 